\title{
OS DESAFIOS PÓS-MODERNOS DA FILOSOFIA LATINO-AMERICANA
}

\author{
[ 'Post-Modern' challenges of Latin American Philosophy ]
}

\author{
Carlos Alberto Gomes * \\ Universidade Nova de Lisboa, Portugal
}

\begin{abstract}
Resumo: Resumo: Pode-se considerar que a filosofia intercultural constitui uma etapa evolutiva da filosofia da libertação latinoamericana (FL), dinamizada pelo argentino Enrique Dussel. Em oposição ao que predomina na tradição filosófica ocidental, de pendor centralista, racional e etnocêntrico, a filosofia intercultural incorpora todas as particularidades (circunstâncias) e tradições regionais (contextos), focalizando-se numa dimensão plural e não homogénea do conhecimento e da cultura humanas. A filosofia interculturalista desenvolvida por Raul FornetBetancourt aponta a necessidade de estabelecer uma base dialógica entre as diferentes tradições a partir dos princípios universalistas do respeito, tolerância e conhecimento mútuo, sendo considerada uma alternativa válida e tipicamente latino-americana, ao 'pensamento único'.
\end{abstract}

Palavras-Chave: Capitalismo; Circunstância; Filosofia da libertação; Interculturalismo; pósModernidade
ABSTRACT: Abstract: It can be considered that intercultural philosophy constitutes an evolutionary stage of the philosophy of Latin American liberation (FL), spurred by the argentine Enrique Dussel. In opposition to what prevails in the western philosophical tradition of centralist character, rational and ethnocentric, intercultural philosophy incorporates all particularities (circumstances) and regional traditions (contexts), focusing on a plural and inhomogeneous dimension of knowledge and human culture. The interculturalist philosophy developed by Raul Fornet-Betancourt points out the need to establish a dialogue basis between the different traditions, from the universal respect principles, tolerance and mutual understanding, and is considered a valid alternative and typically Latin American, the 'single thought '.

KEYwORDS: Capitalism; Circumstance; Philosophy of liberation; Interculturalism; PostModernity.

\section{A Filosofia da libertaÇÃo COMO PARAdigMa de UMA ATITUdE Pós- RACIONAL}

Dode dizer-se que a Filosofia da libertação é o 'cartão de visita' do chamado pendor crítico relativamente a alguns aspectos do ideário do pensamento atual, nomeadamente europeu-ocidental, é algo a ter em conta. Na verdade, a Filosofia da libertação, enquanto teoria identitária do pensamento latino-americano, refuta a

* Investigador integrado no CHAM Centre for Global History,da Faculdade de Ciências Sociais e HumanasFCSH/NOVA, no grupo de investigação 'Cultura e história do pensamento ibéricos e iberoamericanos'. Doutorado em Filosofia (área da especialidade: Filosofia da Cultura),pela Faculdade de Ciencias Sociais e Humanas da Universidade Nova de Lisboa. m@ilto: cgomes@fcsh.unl.pt 
elaboração dogmática dos fundamentos dos direitos humanos, enquanto instrumento ideológico, vendo-os como o resultado de um processo dialético, ou seja, de um logos histórico que se vai ' atualizando' na(s) circunstância(s) dessa praxis ${ }^{1}$.

Considero que a Filosofia da libertação é uma 'alternativa' no quadro das correntes do pensamento dito 'pós-Moderno' que aceitam, para não dizer, defendem, a lógica de um 'pensamento fraco' e de uma 'aligeirização' dos pressupostos filosóficos últimos da racionalidade (a questão do sentido). É libertadora porque parte da própria função 'sagrada' da filosofia que é a busca dos fundamentos últimos para a partir daí, denunciar e criticar a 'má-consciência' de todas as construções ideológicas que legitimam dogmaticamente as teorias da alteridade e que sustentam a(s) desigualdade(s). Embora situando-se temporalmente no mundo contemporâneo, dito 'pós-Moderno', a Filosofia da libertação tenta a consciencialização do erro, que foi o acreditar no progresso linear e infinito que o capitalismo traria, através do saqueamento e apropriação de recursos naturais.

Nesta base podemos recordar, como exemplo, o argentino Enrique Dussel (1934?) $)^{2}$, a maior figura desta filosofia, quando assinala que o 'Homo homini lúpus' é a definição real e política, da racionalidade cartesiana (o 'cogito') típico da filosofia europeia moderna e contemporânea. Torna-se expressão ontológica da ideologia da 'burguesa', triunfante na revolução inglesa, e que dominará o mundo no modo de produção capitalista uniforme. É por isso que, num primeiro momento, Dussel considerava a filosofia da libertação como uma filosofia pós-moderna, pois buscava superar a ontologia conquistadora da filosofia moderna.

Dussel é um grande defensor da necessidade de rutura do modelo filosófico 'eurocêntrico', argumentando que o estudo do homem e das culturas, especialmente da Modernidade e feito pelos cientistas do 'Norte', não serve para a realidade do Outro, representada pela grande massa da humanidade existente na América Latina, Ásia e África, onde estão os verdadeiramente 'excluídos', injustiçados e distantes de integrarem a totalidade, representada pelos do Norte. O apelo à 'libertação' significa estabelecer uma relação de diálogo com a 'humanidade', ou seja, com os representantes da 'humanidade' do 'norte'. Para a Filosofia da libertação, o que importa é o ser do outro, daquele que está fora da totalidade, fora do sistema, enquanto 'excluído', havendo pois, a necessidade de um amor gratuito, um amor puro e criador que vá além do horizonte ontológico. Pode dizer-se, em resumo, que Dussel foi um crítico assumido da pós-Modernidade, e do pensamento eurocêntrico 'totalitário'. O seu momento foi sempre o do 'agora', da decisão, do compromisso e da responsabilização éticas, numa linha que poderemos apelidar de 'marxismo crítico'.

Não há dúvida que as três grandes promessas da Modernidade - a promessa da igualdade, liberdade e dominação da natureza - não se concretizaram nem trouxeram consequências muito desejáveis. A igualdade vê-se manifestamente contrariada pela pobreza do Terceiro Mundo ou pelos sectores marginalizados das sociedades do chamado 'primeiro Mundo', a liberdade não se clarificou diante da violência policial, do trabalho infantil ou das suas condições pouco dignas, dos conflitos raciais contra as minorias, da violência sexual, do primado securitário, ou das crises de refugiados e migrantes asiáticos. A dominação da natureza, por sua vez, realizou-se de maneira perversa, ao destruir o próprio ambiente e provocar graves desajustamentos ecológicos que têm vindo a causar cataclismos a níveis metereológico, só para dar um exemplo.

Diante desta crise, há quem considere que a defesa da Modernidade é um 'poço sem fundo' já que a situação é cada vez mais complexa, a vários níveis, ou como diz, U. Beck, vivemos numa 'sociedade de risco' contra a qual apenas podemos minimizar as suas nefastas e prováveis consequências. 
Neste sentido, embora hajam grandes virtualidades a reconhecer nos teóricos críticos da Escola de Frankfurt, eles não foram capazes de reconhecer que "a razão que critica não pode ser a mesma razão que pensa, que constrói e que legitima aquilo que é criticável". É este o grande dilema da contemporaneidade: falta um distanciamento entre sujeito e objecto que permita a consciencialização da diferença!

Segundo Dussel, dever-se-á desenvolver uma filosofia olhando para a própria circunstância e realidade, encarando-se os problemas frontalmente tal como fizeram os europeus, tentando dar respostas às suas próprias inquietações, oriundas do seu próprio contexto sócio-histórico, económico e cultural. Não obstante, a filosofia deve indubitavelmente tornar-se uma filosofia social, pois não faria sentido em plena contemporaneidade produzir-se uma filosofia metafísica da vida, alheada da praxis histórico-social. Por isso, Dussel considera que o filósofo não tem não só um papel de libertar, mas de consciencializar, não apenas um papel de ensinar, mas ser um elemento solidário, a partir da tomada de consciência de um olhar critico, sobre a sua realidade e circunstância.

É por isso que se tenta ver o significado desta 'filosofia sul-americana' da libertação, como uma oportunidade de consciencialização crítica à globalização que marcha a grande velocidade, na sua estratégia dominadora travestida de felicidade, pluralidade e democracia, mas que todavia mais não são do que capas de pensamento único e desejo de controlo global. Deste modo, podemos considerar a fillosofia de libertação (adiante designada FL) como um espaço pós-Moderno alternativo.

A FL em meados do séc. passado começou a romper com o paradigma racionalista das 'ideias claras e distintas' cartesianas, já que se propôs assumir um logos historico capaz de responsabilizar-se pela realidade, através da praxis histórica. Todavia, a FL não renunciou na sua busca dos valores modernos da igualdade e da liberdade, considerando que ambos deviam sempre fazer parte integrante do ethos dignificador de um processo libertador, conducentes à justiça social e à solidariedade.

A dignidade da vida é o fundamento nuclear da libertação espiritual da pessoa humana, o qual não se compadece com uma lógica de pobreza e regressão social, e que se tornou parte integrante dos malefícios des-estruturantes da (pós) Modernidade capitalista. A FL, nesta perspectiva, pretende ser uma filosofia pós-Moderna alternativa, que opta pela defesa dos princípios verdadeiramente humanistas (as pessoas), e não tanto das estruturas facticas que oprimem e escravizam mentalmente o Homem e as respetivas estruturas sociais (o sistema).

$\mathrm{Na}$ verdade, a FL não pode caír nos reducionismos fáceis e ilusórios da 'bondade' pós-Moderna da liberdade e dos caprichos individuais. Em vez disso, deve atentar na realidade autêntica dos direitos humanos. Direitos humanos vistos não como capa 'ideológica', mas direitos humanos reais e vividos. Não se pode ficar refém de reducionismos cerceadores e mistificadores da realidade prática, embrulhados de teias sedutoras de vantagens 'egoistas' momentâneas (económicas), mas ter sempre em conta o futuro mais amplo, o autêntico horizonte 'pós-Moderno' em que todos os direitos humanos sejam respeitados e defendidos: éticos, sociais, culturais, políticos, jurídicos e, claro está, também os económicos.

Estamos face à velha questão do etnocentrismo. A herança da FL deve superar não só essa visão distorcida e etnocêntrica, meramente abstrata, mas possibilitar a sua historização no âmbito intercultural, ou seja, de cada cultura particular. Não é hoje defensável uma visão fechada da vida das várias culturas, mas sim uma lógica plural e transversal de encontro cultural, que dinamizem mudanças e enriquecimentos.

Isto significa que a herança da FL porá de lado qualquer tipo de 'ideologização dos direitos humanos', simplesmente funcionais e colocados ao serviço dos interesses 
dos poderosos (EUA, mundo ocidental, em geral) como aconteceu no período da Guerra Fria (anos 70/80), e como parece ser a nova tendência pós-invasão do Iraque.

$\mathrm{O}$ universalismo eurocêntrico deve ser superado pela visão libertadora e plural que permita transcender o quietismo do 'pensamento único' e do conformismo convencional. Como afirmava, sagazmente, o eminente Heraclito de Éfeso, 'toda a vida é feita de devir, de mudança'. Urge avançar e criar novas soluções verdadeiramente humanistas.

Nesta base, a herança filosófica da FL constitui uma forma filosófica pósModerna, mas não convencional e ilusória: real e alternativa. Por outras palavras, depois de séculos nos quais o capitalismo conseguiu homogeneizar e absolutizar várias dimensões da vida humana na esfera económica, impondo um poder e dominação globais, o processo começou a reverter-se. A herança da FL parece ter algum sentido. E esse sentido passa a ser dado por uma nova forma de pensar, por um novo paradigma o paradigma interculturalista.

\section{A Filosofia INTERCULTURALista E OS SEUS PROPÓSitos}

Pode-se considerar que a filosofia intercultural constitui uma etapa evolutiva da filosofia da libertação latino-americana, dinamizada pela figura já referenciada do argentino Enrique Dussel. Iniciada a partir das reflexões de Raul F. Bettancourt (1925?) e desenvolvida igualmente por outras figuras do pensamento sul-americano e europeu, como Santiago Castro Goméz (Colômbia), Hugo Biagini e Horácio Cerutti (Argentina), Franz Hinkelammert (Costa Rica), Franz Martin Wimmer (Áustria) e Heiz Kimmerle (Alemanha), esta nova forma de reflexão filosófica focaliza o conhecimento numa base mais ampla e abrangente (contextual), integrando e não excluindo, os vários 'pensamentos' e diferentes culturas.

Em função deste novo paradigma, a filosofia intercultural manifesta uma dimensão crítica muito acentuada, pois tenta dar resposta prática e ser uma alternativa aos problemas existenciais, integrando questões ligadas à ontologia (estrutura da realidade), epistemologia (cognoscibilidade da realidade), ética (normas e valores) e política (organização da sociedade).

Contrariamente ao que predomina na tradição filosófica ocidental, de pendor centralista, racional e etnocêntrico, a filosofia intercultural incorpora todas as particularidades (circunstâncias) e tradições regionais (contextos), focalizando-se numa dimensão plural e não homogénea do conhecimento e da cultura humana. O objectivo último da filosofia intercultural, baseada também no princípio da interdisciplinaridade é, na verdade, dar novas respostas e constituir-se como uma alternativa aos processos e desafios actuais da globalização económica e homogeneização cultural.

Urge não nos deixarmos apagar na desumanização, fazendo, pelo contrário, com que o homem seja uma parte ativa e integrante do todo (cosmos), e não uma parte decartável neste processo de dominação e reducionismo existencial. Urge, pois, recuperar o 'ethos' ibero-latino, comunitarista e solidário! Em suma, não se trata de excluir 'o outro', mas de 'interpretá-lo', concebendo a vida e a cultura como um enriquecimento dinâmico e dialéctico, de transformação e libertação do homem, visando a sua autonomia e consciencialização racionais.

\section{OS FUNDAMENTOS BÁSICOS DA FILOSOFIA INTERCULTURALISTA}

A história recente do desenvolvimento da filosofia interculturalista na Europa, 
tem o seu início por volta dos finais dos anos 80 e princípios de 90 do século passado, altura em que aparecem as primeiras publicações de Raul F-Betancourt. Estas obras mostram-se relativamente complexas, tendo em conta a inovação epistemológica e a transformação radical do conhecimento e compreensão da realidade que implicam. Nesta base, poder-se-iam sinalizar dois fundamentos básicos ou pressupostos, a saber:

- Ruptura com os modelos filosóficos mono e unilaterais, assentes no princípio ontológico da existência de uma realidade a priori (física ou metafísica), a qual vincula o princípio da verdade absoluta e objectiva, cujo sentido corresponde iconicamente a uma realidade prévia;

- Superação dos mitos universalistas e simplificadores dos racionalismos ocidentais e eurocêntricos. Estes traduzindo-se em falsos dualismos, provocam o desencadear das oposições e hierarquias que legitimam a superioridade de uns e que 'exploram' os outros. Esta superação dos dualismos visa alcançar uma dimensão contextual da reflexão filosófica, norteadas pelo pluralismo das racionalidades e pela conceção dinâmica de todas as formas de sensibilidade espácio-temporais.

Há que notar que a filosofia intercultural entronca num construtivismo epistemológico, na base do qual se podem recriar, destruir ou renovar diferentes realidades múltiplas e plurais, rompendo-se com a ontologia do dado. O conhecimento que antes era considerado uma simples correspondência gráfica e linear entre saber e realidade, converte-se agora em interacção construtiva e funcional de múltiplas realidades (plurais, ativas, complexas e globais). Esta lógica trans e interdisciplinar favorece pois, uma reflexão permanentemente crítica e inconformista no constante diálogo entre saber e vida ${ }^{3}$. Hoje, não podem existir redutos fechados ou fronteiras formais de cientificidade no saber que só dividem o pensar e o conhecimento, em compartimentos artificiais.

A interdisciplinaridade segundo a filosofia interculturalista, propõe pragmaticamente a construção e o desenvolvimento do diálogo entre diferentes campos comuns e globais do saber, os quais visam impedir qualquer tipo de 'imperialismo cultural'.

\section{Santiago CaStro-Goméz e a PóS-Modernidade latino-AMERICANa}

Como atrás se disse, a temática da pós-Modernidade na América Latina iniciouse na década de 80 , e reforçou-se significativamente a partir dos anos 90 do século passado. Bastante desconhecidos na Europa, foram feitos importantes estudos sobre a questão, levado a efeito por filósofos e sociólogos latino-americanos. Estes puseram o acento tónico no papel da evolução técnico-científica e computacional, aliadas a uma ética crescentemente individualista.

O colombiano Santiago Castro-Gómez (Bogotá, 1958) é uma dessas figuras. Tendo a sua fonte inicial na filosofia europeia (Escola de Frankfurt, Foucault e Deleuze), basicamente aceita a ideia de fragmentação, heterogeneidade e pluralidade do ímpeto racionalista que afogou os grandes relatos universalistas e abstratos, algo, pois, comum a tudo o que foi considerado por todos os pensadores europeus, como Gilles Lipovetsky.

Santiago Castro-Gómez defende a pertinência da existência de um paradigma pós-Moderno latino-americano, em oposição às teses da Filosofia da Libertação (Dussel), pois considera já as mesmas desajustadas face à atual realidade latinoamericana. Na sua obra mais relevante, 'Crítica da razão latino-americana' (1996), problematiza a teoria da dependência e da culpabilidade histórica e única de todos os 
seus males ao Primeiro Mundo (Europa), bem como a tese (social) do antagonismo de classes visando a utopia de uma nova filosofia para a libertação ${ }^{4}$. Hugo Biagini transporta essa ideia para um campo mais problematizador e hermenêutico ${ }^{5}$, enfatizando a dimensão critico-dialética de um utopismo humanista. Mais do que uma 'mudança de sensibilidade' a nível do mundo da vida, existe a consciencialização da necessidade de uma mudança geral e universal ${ }^{6}$. Esta nova sensibilidade pode ser caracterizada, segundo Santiago Castro-Gómez a a partir dos seguintes princípios.

1. Ceticismo geral perante os ideais heróicos típicos da geração anterior (moderna), tendo em conta o fracasso dos ímpetos libertacionistas latino-americanos;

2. Passagem de uma cultura holista, a outra de teor neo-individualista, centrada não em identidades amplas (nação, continente, ideologia), mas em outras mais restritas e priváticas (grupos, família, amigos);

3. Identidade nacional dissolvida em identidades supra-nacionais, muito por causa da influência dos media;

4. Fomento de uma cultura de 'pensamento débil' ou de 'imediatez', profundamente cética face às meta-narrativas salvíficas e libertadoras;

5. Abandono da militância política das lutas de libertação, para a prática de acções mais individuais (espetaculares) de auto-satisfação pessoal (música, video, desportos radicais);

6. Surgimento de uma 'sensibilidade pessimista', intrínseca ao espírito do homem atual, o que faz aceitar como natural a predominância de critérios estéticopublicitários no seu imaginário simbólico-cultural;

7. Incremento de uma socialização intensiva e massiva, que dilui a distinção entre alta cultura e cultura popular;

8. Consciência do fracasso de todos os projetos de transformação social afiliados pela racionalidade ilustrada (justiça social, igualdade, defesa dos pobres).

Em conclusão, na linha descritivo-analítica do francês Gilles Lipovetsky, o qual constitui uma espécie de alma gémea europeia, Santiago Castro-Gómez considera que a pós-racionalidade é um 'estado de alma', mais que de um mero neo-liberalismo, bem distante da tendência uniformizadora moderna. Baseado na ideia de poder, de Foucault, ('não há poderes bons ou maus, mas apenas um jogo de forças que atravessa dominadores e dominados), o pensador colombiano também pensa que todo o combate pela justiça pode gerar injustiças.

O futuro tem que passar pelos princípios do consenso, harmonia, reconciliação e diálogo, considerados na utopia de um mundo policêntrico (económico-político) e pluralista (cultural), o que confirma a validez das teses interculturalistas de Raul FBetancourt, cujo élan assentava na força da racionalidade comunicativa de J. Habermas.

Pelas razões aduzidas, dever-se-á dizer que a filosofia interculturalista constitui a imagem efectiva e actual do pensamento pós-Moderno latino-americano!

\section{REFERÊNCIAS}

ALBARES, Roberto (e outros). Filosofia hispánica y diálogo intercultural, Fundación Gustavo Bueno, Universdad de Salamanca, Faculdad de Filosofia, 1996.

ANDERSON, Perry. As Origens da Pós-Modernidade, Edições 70, Colecção Arte e Comunicação, tradução do original 'The Origins of Postmodernity', (1998), por Artur Morão, Lisboa, $1^{\text {a }}$ edição, 2005.

BAUDRILlARD, Jean. A Sociedade de Consumo, Edições 70, Colecção Arte e Comunicação, tradução do original 'La Société de Consommation', por Artur Morão, Lisboa, $3^{\mathrm{a}}$ edição, 2008 . 
BETANCOURT, Raúl Fornet e BEORLEGUI, Carlos. Filosofia Latinoamericana, Editorial Comares, S.L. Colección Guía Comares, 5, Granada, 2014.

GOMES, Carlos A. Filosofia e Cultura Luso-Hispânica, E-book, Formato EPUB, $1^{\text {a }}$ edição WordPress, Plataforma Liveinternet, 2014.

GUIDDENS, Anthony. O mundo na era da globalização, Editorial Presença, tradução do original 'Runaway World' (1999), por Saul Barata, Lisboa, 7ª edição, 2010.

GULDBERG, Hoacio Cerutti. Filosofia de la liberación latino-americana, Tierra Firme, Fondo de Cultura Económica, México, $1^{\mathrm{a}}$ edición, 1983.

HABERMAS, Jurgen. Técnica e Ciência como 'Ideologia', tradução do original Technick und Wissenschaft als 'Ideologie' (1968), por Artur Morão, Edições 70, Colecção Biblioteca da Filosofia Contemporânea, Lisboa, $1^{\text {a }}$ edição, 1994.

LIPOVETSKY, Gilles. A Era do Vazio, Relógio de Água, Colecção Antropos, tradução do original 'L'Ere du Vide' (1985), por Miguel Serras Pereira e Ana Luisa Faria, Lisboa, $1^{\text {a }}$ edição, 1988.

LIPOVETSKY, Gilles e Sebastien, Charles. Les Temps hypermodernes, Éditions Grasset \& Fasquelle, Biblio Essais, Collection Livre de Poche, Paris, 2ème édition, 2008.

GASSET, Ortega y. La Rebelión de las Masas, Espasa-Calpe, Selecciones Austral, Madrid, $5^{\text {a }}$ edición, 1984.

\section{Notas}

1 Poderíamos sintetizar essas particularidades em três pontos: “a) Um filosofar específico nascido da sua própria circunstância e passado, feito de dominação;

b) Um filosofar eminentemente práxico e vivencial, nascido de uma matriz estético-emocional, tipicamente de periferia;

c) Um filosofar tendencialmente ético e humanista, nascido das condições de dependência historicamente colonial e culturalmente eurocêntrica.", Carlos A. Gomes, Problemata, Rev.Internacional de Filosofia,v.7 n. 1 (2016), p. 273-275.

2 Assim, Dussel focaliza a sua atenção sobre o assunto da libertação, ou seja, desenvolve a sua reflexão sobre a problemática concreta da realidade dos povos latinos. Não é tanto sobre o aspecto conceptual ou teórico da questão, que ele se preocupa. Dussel afirma, como ponto central de seu pensamento, que deve ocorrer uma verdadeira libertação do pensamento latino, que mantém uma notória submissão à filosofia europeia, e por outro lado deve concretizar a libertação do 'trabalhador explorado', Carlos A. Gomes Filosofia e Cultura Luso-Hispànica, in http://filcarlos.com/dussel-e-o-problema-essencial-da-filosofia-dalibertacao/

3 “A caracteristica intercultural da filosofia implica para Raul Betancourt uma disposição dialógica, de renúncia ao monolinguismo ou qualquer tipo de racionalidade únicas. Ao mesmo tempo, Betancourt considera que a filosofia intercultural deve constituir um método ou compromisso ético-político que produza mudanças ao nível das complexas relações internacionais, face à globalização, com o propósito de introduzir o princípio da diversidade e pluralidade." Carlos A. Gomes, Filosofia e Cultura Luso-Hispânica , in http:/filcarlos.com/filosofos-hispanicos/raul-f-betancourt-cuba/

4 "O colombiano Santiago Castro-Gómez considera que a questão fundamental que subjaz à problemática de uma filosofia ibero-americana, não é tanto a de saber se existe ou não uma condição pós-Moderna, mas a de analisar as alternativas que se colocam a ela." Idem, in http://filcarlos.com/o-espirito-da-pos-modernidade-no-continente-americano/

5 "A corrente "problematizadora" colocou a ênfase na questão epistemológica, procurando questionar radicalmente o próprio discurso e, ao mesmo tempo, verificá-lo. Reflete sobre o problema da linguagem, da ideologia e o problema metodológico. Como representantes desta corrente podem-se mencionar José Severino Croatto, Manuel Ignacio Santos, Hugo Biagini, Gustavo Ortiz, Hugo Assmann e Augusto Salazar Bondy." Idem, in http://filcarlos.com/cerutti-e-as-correntes-integrantes-da-fl/

6 "Hugo Biagini, por sua vez, sublinhou a dimensão alternativa e problematizadora de um 
modelo filosófico para a libertação, e não apenas da libertação. A perspetiva interculturalista e alternativa ao modelo eurocêntrico e monocultural, assentou as suas baterias no esclarecimento e desmistificação das linguagens falazes e ilusórias dos media, promovendo o interesse e a importância acrescidas, da critica ao situacionismo. Por esta via, os interculturalistas criaram a categoria do 'utopismo' através da qual tudo deve e pode ser posto em questão dialeticamente, já que a condição de questionamento e inconformismo humanos devem levá-lo a um patamar de superação da condição presente. A crítica, embora nunca concluída, é algo imanente ao desejo de superação do erro totalitário do 'pensamento 'único', razão pela qual os seus defensores consideram urgente a sua ultrapassagem.” (Carlos A. Gomes, Colóquio Internacional 'Gerações Hispânicas' in http://filcarlos.com/i-coloquio-internacional-geracoes-hispanicas-sintese-dacomunicacao/ 